\title{
ROOT CANAL TREATMENT USING THREE DIMENSIONAL FILLING WITH GUTTA PERCHA
}

\author{
Lauren Muhametaj ${ }^{1 *}$, Rozarka Budina $^{2}$

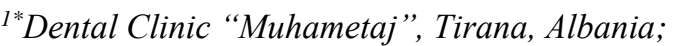 \\ ${ }^{2}$ Faculty of Dental Medicine, Tirana, Albania; \\ *Corresponding author: Lauren Muhametaj, e-mail: dr.aferdita@gmail.com; \\ Received September, 2018; Accepted September, 2018; Published October, 2018; \\ DOI: https://doi.org/10.31407/ijees8427 \\ UOI license: http://u-o-i.org/1.01/ijees/91452516
}

\begin{abstract}
Successful root canal treatment depends critically on controlling pulp-space infection. Three dimensional filling with gutta percha results in a uniformed smooth surface and least observable space between gutta-percha and canal walls especially in middle and apical region of the root canal. The aim of this study was to evaluate the success rate of three dimensional root filling with gutta percha. Among the 71 study teeth filling using three dimensional guttapercha, 67 were clinically sound and did not have signs and symptoms suggesting failure at the evaluation. The success rate was thus $94.4 \%$. An ideal root canal filling three-dimensionally fills the entire root canal system as close to the cemento-dentinal junction as possible. Three dimensional filling with gutta percha are effective in filling canals with a high rate of success.
\end{abstract}

Key words: gutta-percha, three dimensional, root filling 